\title{
O Ensino da Matemática no processo de Oficinas de Aprendizagem
}

Priscila Dombrovski Zen

Joyce Jaquelinne Caetano

\begin{abstract}
Resumo
Este trabalho teve por objetivo realizar uma investigação sobre o processo de ensino-aprendizagem da disciplina de Matemática realizado nas oficinas de aprendizagem do Colégio SESI (Serviço Social da Indústria) na cidade de Irati - PR. Inicialmente, realizou-se uma pesquisa bibliográfica sobre a proposta da metodologia aplicada sua trajetória em território paranaense bem como a menção dos procedimentos de gestão e pedagógicos nesse processo de ensino, com base em estudiosos dessa área. A seguir, realizou-se uma entrevista com os docentes da disciplina de Matemática sobre a dinâmica realizada nas aulas, apontando suas opiniões sobre essa metodologia. Verificou-se, a partir das análises realizadas, as dificuldades que os professores sentem com a aplicação dessa metodologia diferenciada, bem como o sucesso no rendimento dos alunos quando superados tais obstáculos.
\end{abstract}

Palavras-chave: Matemática, Metodologia, Oficinas de Aprendizagem.

\section{Abstract}

The teaching of mathematics in the process of Learning Workshops

This study aimed to conduct an investigation into the teaching and learning of Mathematics held workshops on learning the College SESI (Social Service of Industry) in the city of Irati - PR. Initially, we performed a literature search on the proposal of the methodology applied in its trajectory territory of Paraná and the words of management procedures and teaching in the teaching process, based on scholars in this area. Then, there was an interview with the faculty of Mathematics held on the dynamics in the classroom, pointing their opinions on this methodology. It was found from the analyzes, the difficulties that teachers experience in applying this methodology differentiated and success in student achievement when overcome such obstacles.

Keywords: Mathematics, Methodology, Learning Workshops 


\section{Introdução}

As mudanças que vêm ocorrendo no universo do trabalho têm colocado novos desafios para a educação: já não basta mais ensinar, é preciso preparar o educando para a inserção em sociedades cada vez mais complexas e estar preparado para atuar de modo produtivo, inovador, ético e transformador.

Com esse intuito o Colégio SESI (Serviço Social da Indústria), foi implantado no ano de 2005 no Estado do Paraná, alinhado com as políticas públicas nacionais, em que o Governo Federal em 1996, por intermédio do Ministério de Educação e Cultura (MEC), iniciou um processo de mudança no Ensino Médio. Pela Lei n. 9394/96 (LDB), o Ensino Médio passa a ser considerado Educação Básica. A faixa etária idealizada para a implantação do Colégio foi o Ensino Médio, pois a mesma estabelece a perspectiva de que para esse nível de ensino deve haver a oferta, de forma articulada, de uma educação equilibrada entre a educação básica e a preparação para o mercado de trabalho, com funções equivalentes para todos os educandos.

As necessidades apresentadas pelo mercado de trabalho, em especial pelo setor industrial instigou o Presidente da Federação das Indústrias do Estado do Paraná (Gestão 2003-2011), em qualificar profissionais para as Indústrias, oportunizando um aprendizado diferenciado, que tornasse o educando um ser empreendedor, investigador, dinâmico, e que desenvolvesse habilidades no trabalho em equipes e não apenas com foco principal em aprovações de vestibulares.

Nessa direção, a Professora Marcia Conceição Rigon, no ano de 1990, implantou na cidade de Montenegro - RS, a metodologia de Oficinas de Aprendizagem no Colégio em que era diretora. Como citado na cartilha "projeto e identidade" do Colégio SESI.

A partir do êxito desta experiência, é que em 2005 foram implantadas duas unidades como experiência-piloto nas cidades de Curitiba e São José dos Pinhais. Diante do impacto de sua proposta, ampliou-se nos anos seguintes para mais cidades do Estado. Até o ano de 2010 já totalizavam 41 unidades, incluindo a unidade implantada na cidade de Irati no ano de 2007.

As políticas implantadas no Colégio SESI por sua vez, assumem uma tarefa educacional de ensinar a cada um na medida de suas possibilidades, dando opções e oportunidades de aprender conforme suas capacidades e suas inteligências. Objetivando a preparação de alunos empreendedores e aptos para tomada de decisões, tornando-o autônomo e agente de sua aprendizagem.

Nessa perspectiva, essa pesquisa teve por objetivo estudar a metodologia de Oficinas de Aprendizagem implantadas no Colégio SESI, a qual faz uso de algumas tendências da Educação Matemática, como Resolução de Problemas, Modelagem Matemática e trabalho em 
grupos/equipes, bem como identificar as dificuldades enfrentadas pelos professores de Matemática da Instituição.

Para tanto, buscou-se aprofundamento sobre a metodologia de ensino do Colégio SESI e a dinâmica de trabalho dessa instituição, desde como são organizadas as turmas, as orientações indicadas no projeto político pedagógico e a elaboração das Oficinas de Aprendizagem.

Além disso, foram entrevistadas duas professoras de Matemática do Colégio SESI, atuantes no Ensino Médio no intuito de obter informações sobre as dificuldades iniciais vivenciadas com a metodologia de Oficinas de Aprendizagem; o trabalho em equipe (alunos e professores); disciplina dos alunos; aplicabilidade em outra instituição de ensino, preparação das rotas de aprendizagem e quais as melhorias que os cursos de licenciatura podem realizar.

\section{Fundamentação Teórica}

Desde a década de 50 até meados dos anos 70 foram marcados pela grande expansão na pesquisa em Educação Matemática em todo o mundo. A esse respeito Segundo Kilpatrick (1996, p.102),

O movimento da 'Matemática Moderna' contagiou muitos países, despertou a elaboração de periódicos, novas organizações profissionais, novos institutos de pesquisa para a Educação Matemática e um exercito de novos pesquisadores.

A partir da década de 80, novas concepções educacionais, propostas por diferentes educadores, especialmente Paulo Freire, são postas em discussão, como a dimensão histórica do saber, a importância do diálogo e a problematização do conhecimento no ambiente escolar. Surgem, então, algumas tendências para o ensino e a aprendizagem da Matemática, como a Etnomatemática, a Modelagem Matemática, a Resolução de Problemas, as Tecnologias da Informação e da Comunicação, a História da Matemática, contextualização, interdisciplinaridade, entre outros.

Dentre essas propostas o Colégio SESI, apresenta em seu projeto político pedagógico, a resolução de problemas e a Modelagem Matemática como metodologias norteadoras das ações do professor.

Entendemos que as Oficinas de Aprendizagem, mediante problemas/desafios, procuram desenvolver e mobilizar competências de forma contextualizada e significativa e complementa, conforme a cartilha (Colégio SESI-Proposta Pedagógica, 2011, p.63-64)

As Oficinas de Aprendizagem mobilizam competências já adquiridas, promovem o desenvolvimento de habilidades e provocam a aprendizagem significativa ao estabelecer uma relação de reciprocidade entre o aluno e o 
objeto do conhecimento expresso na situação-problema/desafio real, levando os alunos a fazerem a transposição didática do que já sabem da teoria para a prática e vice-versa.

Essas propostas do SESI encontram respaldo legal nos Parâmetros Curriculares Nacionais - Matemática Brasil, (1997 p. 43) pois, conforme esse documento, "no processo de ensino aprendizagem, conceitos, ideias e métodos devem ser abordados mediante a exploração de problemas, ou seja, de situações em que os alunos precisem desenvolver algum tipo de estratégia para resolvê-las". Desse modo, as orientações contidas nos PCNs explicitam uma concepção de ensino de Matemática, pautada na construção, ressignificação e compreensão de conceitos, em oposição ao trabalho diretivo, mecânico e descontextualizado.

Para Smole e Centurión, (1992, p.9),

É, pois, fundamental que o estudo da Matemática seja calcado em situaçõesproblemas que possibilitem a participação ativa na construção do conhecimento matemático. $O$ aluno desenvolve seu raciocínio participando de atividades, agindo e refletindo sobre a realidade que o cerca, fazendo uso das informações de que dispõe. Se quisermos melhorar o presente estado de conhecimento, devemos nos questionar sobre como pode, de fato, o nosso aluno desenvolver o pensamento crítico ou raciocínio lógico.

Além de desenvolver as aptidões destacadas anteriormente, Onuchic e Menino (2011, p.4), complementam essa ideia;

A primeira característica é considerar como problema toda situação que permita alguma problematização. A segunda característica pressupõe que enfrentar e resolver uma situação-problema não significa apenas compreender o que é exigido, a aplicação de técnicas ou fórmulas adequadas e a obtenção da resposta correta, mas, ao que foi proposto como obstáculo a ser enfrentado e até à própria resposta encontrada. A terceira característica implica que a resposta correta é tão importante quanto a ênfase a ser dada ao processo de resolução, permitindo o aparecimento de diferentes soluções, comparando-as entre si e pedindo que os resolvedores digam o que pensam sobre ela, expressem suas hipóteses e verbalizem como chegaram à solução.

Para complementar as três características mencionadas Zorzan (2004, p.200), destaca que "a aprendizagem como ação significativa representa a interconexão, entre o saber cultural, o saber experienciado e o saber científico, dos quais devem emergir saberes e ações interventivas para o contexto vivido".

Esse processo de aplicabilidade ganha ênfase maior quando realizada em grupos, pois conforme cita Volquind (2001), "temos três tipos de mediação a ser realizada pelo professor: 
mediação oral, mediação instrumental - realizada com materiais didáticos - e mediação por meio da interação social (em duplas, trios ou grupos maiores)".

Nesse sentido, os trabalhos em grupos/equipes são importantes, como destaca Chireia $(2010$, p.3),

Resolução de Problemas pode se tornar ainda mais eficiente quando a dinâmica da aula envolve o trabalho com pequenos grupos de alunos. $O$ trabalho em grupo pode trazer uma série de vantagens, como por exemplo, a possibilidade de observar as diferentes estratégias adotadas pelos parceiros ao enfrentarem um mesmo problema. Nessa estratégia, a análise dos procedimentos utilizados e a das atitudes tomadas pelos alunos se constitui em vasto material para a avaliação da aprendizagem.

Quanto a elaboração e a resolução de situações problemas pode ser, realizada individualmente ou em grupos pequenos, sendo posteriormente agrupados em uma lista para serem discutidos e resolvidos. Os problemas podem envolver quaisquer conteúdos que sejam do domínio dos alunos.

A esse respeito Mandel (1994,p.10) afirma ser positivo o fato de que neste procedimento:

Os tópicos abordados nos problemas refletem interesses pessoais dos alunos, como os esportes que praticam os conjuntos de musica que mais gostam preços de roupas, carros, vídeo-game, etc., tornando os enunciados mais significativos para eles. Num livro didático, tais problemas seriam considerados frutos de descuido ou despreparo do autor e, como tais, seriam descartados. Nas listas, a coerência de um problema defeituoso é aceitável, e o problema é discutido como todos os demais. Discernir entre o que é necessário, e o que não é, faz parte da boa resolução de problemas em qualquer área, não só em Matemática.

Com essa metodologia os alunos se dão conta que falhas são aceitáveis e portanto criam maior segurança para resolverem problemas em outras situações e passam a acreditar que a possibilidade do erro pode ser natural.

Rigon (2010, p.101) define essa organização como "times de trabalho" e acrescenta que os alunos devem se sentir bem nesse time, que são importantes para a sua equipe, gerando assim a confiança e aumentando a autoestima.

Equipes de qualidade organizam e gerenciam atividades com responsabilidade e eficiência e trabalham efetivamente no grupo, fazendo as tarefas. A contribuição de cada um para a execução é de qualidade, de excelência. 
Na mesma direção, Burak (2004, p. 3) afirma que;

(...) a proposta de trabalho em grupo possibilita "uma dinâmica maior no ensino, pela ação e o envolvimento do próprio grupo na perspectiva da busca e da construção do conhecimento e para a socialização desse conhecimento dentro do grupo, e posteriormente aos demais grupos. O trabalho com a Modelagem Matemática parte de temas, propostos pelo grupo, ou por grupos constituídos por 3 ou 4 participantes.

Dentro desses parâmetros, o ensino de Matemática torna-se mais dinâmico, e, em consequência, com maior significado para o aluno e educador. Dessa forma acaba contribuindo para tornar mais intensa, mais eficiente e mais eficaz a construção do conhecimento por parte de cada aluno participante do grupo e de toda a equipe sobre determinado conteúdo, a partir do conhecimento que cada aluno ou o grupo já possui sobre o tema em discussão.

Com essa concepção acerca da matemática dar-se-á maior significado ao contexto, permitindo e favorecendo o estabelecimento de relações matemáticas, a compreensão e o significado dessas relações.

Percebe-se que a Modelagem Matemática, apresenta-se como uma oportunidade de os alunos indagarem situações por intermédio da Matemática, sem procedimentos fixados previamente.

A esse respeito Caldeira (2004, p.50), enfatiza:

A necessidade dos conhecimentos matemáticos para o indivíduo atuar como sujeito de transformação social e que essa aprendizagem parta do contexto sociocultural do aluno, proporcionando-lhe o desenvolvimento do pensamento lógico, da criatividade, de aprender conceitos e de construir estruturas matemáticas, a fim de compreender a realidade social, histórica e cultural.

$\mathrm{Na}$ busca da transformação social e aprendizagem, e segundo as tendências em Educação Matemática, que priorizam a colaboração das demais disciplinas para a excelência na qualidade de ensino, é que a metodologia de Oficinas de Aprendizagem se organiza, segundo as propostas do Colégio SESI-Projeto Identidade (2011,p.38),

Uma situação ou um problema real, com questionamentos, são propostos pelos professores-ou alunos- e devem ser analisados, estudados, pesquisados $e$ abordados de diferentes maneiras pelos alunos para a construção de uma ou mais soluções.

Para Miquelin (2008) o termo Oficinas refere-se ao lugar onde efetivamente se coloca a mão na massa, onde não existem observadores passivos, mas participantes, interagindo de diferentes formas. 
Na concepção de Rigon (2010, p.43), a respeito da metodologia de oficinas;

A oficina é, portanto, um lugar de fabricação (de conhecimento), de reparação (de velhos conceitos) com muito serviço braçal e mental (tarefas, dever de casa, pesquisas, análises, projetos) com vistas à resolução de um desafio.

Essas Oficinas são organizadas, através de desafios propostos pelos professores, expressos por meio de uma questão e analisada sobre diversos ângulos com intuito de responder ao problema gerado.

Após a escolha dos temas das Oficinas, os professores das disciplinas fazem a apresentação, apontando os conteúdos a serem trabalhados em cada oficina, motivando-os a escolher o qual mais atende suas habilidades.

E como o tema está associado a todas as disciplinas constante na grade curricular, os desafios promovem a inter e a transdisciplinaridade, que segundo (Colégio SESI - Projeto e Identidade, p.38) "as disciplinas se complementam cruzando conceitos e conteúdos ao serem organizadas em torno de unidades globais, de estruturas conceituais e metodologias compartilhadas".

Para D’Ambrosio (2005, p.19), a interdisciplinaridade:

Transfere métodos de algumas disciplinas para outras, identificando assim novos objetos de estudo. Já havia sido antecipada em 1699 por Fontanelle, Secretária da Academia de Ciências de Paris, quando dizia que: "Até agora a Academia considera a natureza só por parcelas (...) talvez chegue o momento em que todos esses membros, dispersos [disciplinas] se unirão em um corpo regular, e se são como se deseja, juntarão por si mesmas de certa forma".

Já Rigon (2010, p.31) afirma que a homogeneização do conhecimento, é a principal característica presente nessa abordagem, e a integração destes conhecimentos se faz pela transdisciplinaridade, que é a forma de abordagem realizada no Colégio SESI.

Essa forma diferenciada de ensino possibilita a interseriação, definida pela proposta pedagógica que segundo Rigon (2010 p.62),

Os conteúdos não são estanques, divididos em séries sequenciais, mas entrelaçam-se, integram-se, complementam-se, tanto nas redes dos campos conceituais das áreas e disciplinas curriculares, como na temporalidade - do início ao final do processo educativo do Ensino Médio (...) é visto como um todo uníssono, um bloco único de aprendizagem a realizar.

Por se tratar de uma metodologia interseriada, em uma mesma oficina podemos encontrar alunos dos três anos do Ensino Médio. Após a escolha da oficina, os mesmos se dividem 
em equipes com cinco alunos, os quais permaneceram juntos até o fim do bimestre. Como a disposição das mesas é em formato sextavado, o lugar restante é reservado ao professor. Visto que este passa a ser o agente de aprendizagem, orientador, facilitador e mediador do processo.

Dessa forma, a nova representação da Educação Matemática reflete uma visão da Matemática como um de seus componentes e não "o componente".

Assim essa metodologia entra em conformidade a aplicabilidade da Modelagem Matemática, que especialmente no Brasil, está ligada à noção de trabalho de projeto. Trata-se em dividir os alunos em equipes, os quais devem eleger temas de interesse para serem investigados por meio da Matemática, contando com o acompanhamento do professor.

\section{Metodologia}

A entrevista realizada com os professores do Colégio SESI- Unidade Irati, deu-se de acordo com a definição proposta por Fiorentini e Lorenzato (2009, p. 121),

O pesquisador, pretendendo aprofundar-se sobre um fenômeno ou questão específica, organiza um roteiro de pontos a serem contemplados durante a entrevista, podendo, de acordo com o desenvolvimento da entrevista, alterar a ordem dos mesmos e, inclusive, formular questões não previstas inicialmente.

Tendo-se um número restrito de professores dessa disciplina, decidiu-se utilizar uma pesquisa investigativa através de entrevista semi-estruturada, com os docentes. Assim sendo, investigou-se: a sua formação, a dificuldade inicial com a metodologia de oficinas de aprendizagem; o trabalho em equipe (alunos e professores); a disciplina dos alunos; aplicabilidade em outra instituição de ensino, e quais as melhorias que os cursos de licenciatura podem realizar a fim de preparar os futuros professores para fazer uso desta ferramenta metodológica.

\section{Analise de dados}

Por se tratar de uma proposta de ensino diferenciada, a matriz curricular do Colégio SESI totaliza 3.167 horas para o curso de Ensino Médio, com disciplinas extras, como: psicologia, línguas (inglês e espanhol), desenho geométrico e produção textual. As duas últimas oferecidas em contraturno.

Além da matriz curricular com carga horária diferenciada, são ofertados programas complementares à educação, estabelecendo dessa forma parcerias com as demais áreas do SESI e do SENAI (Serviço Nacional de Aprendizagem Industrial): SESI Cultural, SESI Jovem Vida, Círculo de 
Diálogos, Cursos Profissionalizantes a partir da 2a série, Hotel de Projetos Inovadores e Mostra Inova. Também poderão atuar na Junior Achievement Paraná, que oferece estudos dos programas de Economia Pessoal, Miniempresas e Bancos em Ações.

As entrevistas foram realizadas com duas professoras, neste estudo denominadas $\mathrm{X}$ e $\mathrm{Y}$. A professora $X$, é graduada pela Universidade Estadual do Centro-Oeste (UNICENTRO) em licenciatura em Matemática, concluiu o curso em 2010, participando do corpo docente do Colégio SESI desde 2011. A professora Y, é concluinte do curso de Licenciatura de Matemática da Universidade Estadual de Ponta Grossa (UEPG), estando no corpo docente desde 2007. Ambas atuam também em outras instituições de ensino.

Segundo os dados coletados na entrevista, constatou-se que por se tratar de uma metodologia diferenciada, as professoras apontaram algumas dificuldades. Ambas citam a importante utilização da aplicabilidade de conteúdos, a contextualização, o famoso 'onde vou usar?', pois na metodologia de Oficinas de Aprendizagem, é essencial que o aluno aprenda através da descoberta e da aplicação dos conteúdos.

Para completar esse pensamento Onuchic $(1999$, p.85) destaca que o aluno;

Compreende que um problema pode ser enunciado como sendo tudo aquilo que não se sabe fazer, mas que existe interesse em resolver, isto é, qualquer situação que leve o aluno a pensar e que Ihe seja desafiadora e não trivial.

A professora $X$ relatou que sentiu dificuldades em aplicar o conteúdo de números complexos em situações problemas, e que solicitou ajuda ao professor do curso técnico do SENAl, cuja parceria é muito bem vista entre os professores, e o mesmo utilizou-se do conteúdo de eletrotécnica para desenvolver uma situação problema, cuja aplicação auxiliou no desenvolvimento da aprendizagem. Daí vem o principio educativo de incorporar e vivenciar a visão do coletivo. "O trabalho em equipe pelos alunos e professores será o diferencial desta proposta" (Freire, 1987).

Outra dificuldade apresentada é a falta de sequencia que o sistema admite, a professora $Y$, citou que ao iniciar o conteúdo de funções quadráticas observou que os alunos não possuíam devido conhecimento em funções afins, e que a diferenciação entre equações, funções e expressões também não era bem definida na concepção dos mesmos. Logo sentiu a necessidade de realizar um feedback, pois acredita que a aprendizagem é realizada no questionamento e na retomada de conteúdos - o que acontece quando eu faço isto?.

Essa questão de deficiência em determinados conteúdos, também é observada quando o professor deixa de ser agente do processo e passa a ser mediador. 
De acordo com Franchi (1993 p.102),

Eles estão acostumados a ver o professor como transmissor de conhecimentos $e$, portanto, têm uma postura passiva em relação à aula. Esperam receber explicações e participar apenas fazendo perguntas ou resolvendo exercícios. Quando o trabalho coloca o centro do processo ensino-aprendizagem nos alunos, e quando os resultados dependem da ação deles, a aula passa a caminhar em ritmo lento, pois eles não estão acostumados a agir e nem sempre sabem o que fazer, ou por onde começar.

A metodologia aplicada em resolução de situações problemas em Oficinas de Aprendizagem é analisada pelas professoras como 'ótima', para o desenvolvimento cognitivo, para a tomada de decisões e para o aprendizado, porém necessita de um tempo maior para o conteúdo ser atingido. Segundo Rigon (2010, p.42) o professor,

Deixa de ser informante, para ser facilitador. Ele incita a aprendizagem. Deixa de ser dominador, para ser Motivador, Incitador, Instigador até. A partir da apresentação do problema, o professor passa a ter o papel de condutor do processo. Ele orienta os passos, a sequencia a ser seguida, pode mostrar possibilidades de caminho, mas ele não faz a aula, ele não dá aula, mas conhece o conteúdo a ser apresentado profundamente e sabe como fazê-lo ser descoberto em toda a sua magnitude, ele é o gestor da aprendizagem.

Complementando o trabalho realizado em sala, é necessário que o aluno adquira responsabilidade. As professoras investigadas relataram que a necessidade de constantes pesquisas, a obrigatoriedade da realização de tarefas domesticas e o entrosamento em equipes, pelas concepções das professoras, passam a auxiliar na organização pessoal em relação às atividades pedagógicas e administração do tempo.

A professora Y, relatou que utilizou o método de aprendizado do Colégio SESI, em suas aulas em outra instituição de ensino, descrevendo que foi essencial quando aplicado em uma turma em que os professores da instituição descreviam como "a pior turma do colégio", obtendo um excelente resultado. Em contraposição a isso, a professora $X$, relatou que quando aplicou a metodologia em outra instituição, o primeiro obstáculo foi a direção do colégio, que não permitiu que a mesma realizasse o trabalho em equipe, afirmando que o mesmo produzia "muito barulho". Isso já é previsto por Rigon (2010, p.102), ao afirmar que,

Para que não aconteçam tantas conversas paralelas ao conteúdo é necessário que os professores organizem as suas rotas de aprendizagem, as quais são elaboradas como se fossem planejamentos bimestrais, essas rotas necessitam estar em conformidade com os temas propostos pelas Oficinas. Observando a 
transdiciplinariedade proposta pelo colégio, o conteúdo a ser incorporado pelo tema em questão, e os métodos utilizados para o aprendizado e avaliação.

No Colégio SESI, na finalização de cada Oficina, ou seja, a cada bimestre, é realizada uma (gincana) em que os alunos demonstram o seu lado artístico, sempre lembrando que os temas das Oficinas necessitam ser o foco das apresentações. Para a obtenção do conceito/nota, são realizadas avaliações, atendendo o esquema proposto pela instituição, $40 \%$ equivale a nota obtida individualmente e $60 \%$ a nota da equipe.

Questionadas sobre a avaliação em equipes, as professoras relataram que funciona em 'partes', pois depende da formação da equipe, umas atendem a expectativa da proposta, e outras apenas vão no 'lombo' dos demais. Para a atividade em equipes são distribuídas avaliações coletivas, ou seja, uma para a equipe, e todos precisam discutir estratégias de resolução. Elas lembram que diferenciam o nível das questões aplicadas nas provas individuais das realizadas em equipes, aprofundando o conteúdo nas atividades realizadas coletivamente. Complementando a questão avaliação, é aplicado um simulado, formulado pela Sede de Colégios SESI, em Curitiba.

Questionadas sobre as inovações em Cursos de Licenciatura, ambas relataram a necessidade de um número maior de aulas envolvendo conteúdos de didática, e a implantação da disciplina de Educação Matemática, já no início da graduação, segundo a professora X, para que os acadêmicos estejam cientes do que é ser professor. A mesma relata ainda que o Curso de Graduação onde ela estudou, possui um enfoque relativo a questão da Educação Matemática, já a professora $Y$ destaca que o curso em que ela concluiu teve muita ênfase em matemática pura. Afirma ainda que aprendeu mais o conteúdo de didática com uma professora de história do que na graduação.

\section{Conclusões}

A Matemática entendida como prática social, fornece possibilidades ao indivíduo de compreender a realidade que o cerca, gerando reflexão, criticidade e ação transformadora. A Matemática possibilita ao indivíduo a aquisição de potencialidades para a interpretação de problemas, proporcionando deste modo, a compreensão de diversas situações que ocorrem no cotidiano, ampliando ainda mais o poder de argumentação diante de questões políticas e sociais.

Entretanto, na escola, em geral, a Matemática é considerada por muitos alunos uma disciplina difícil sem relação com o cotidiano. De acordo com as concepções da Educação Matemática o professor precisa buscar novas alternativas metodológicas e realizar constantes reflexões a respeito da sua prática, no intuito de abordar a Matemática de forma interessante e motivadora para que os alunos aprendam mais facilmente. 
Percebe-se que é fundamental que o professor enfatize e estimule a criatividade de seus alunos, planejando e desenvolvendo seu trabalho através da utilização de diferentes e motivadoras atividades.

Para que isso ocorra o professor precisa ter essa percepção inata, dar asas a criatividade e obviamente ter uma formação que lhe dê meios para trabalhar desta maneira, assumindo a postura de verdadeiro mediador da aprendizagem.

Diante destas considerações, confrontando as propostas da metodologia de Oficinas de Aprendizagem, com as Tendências em Educação Matemática, concluímos que a Modelagem Matemática, a Interdisciplinaridade e a Resolução de Problemas estão presentes de uma forma muito intensa na proposta do Colégio SESI.

Observou-se também que os profissionais que atuam nessa instituição, possuem algumas limitações na inserção da metodologia, mas quando sanadas o trabalho torna-se produtivo e diferenciado, fazendo com que as aulas de matemática se tornem atrativas. 


\section{Bibliografia}

BRASIL. Ministério da Educação e Cultura. Parâmetros curriculares nacionais: ensino médio. Brasília, 1997. 364 p.

BURAK, D. . Modelagem Matemática e a Sala de Aula. In: I EPMEM - Encontro Paranaense da Modelagem Na Educação Matemática., 2004, Londrina. Anais do I EPMEM, 2004.

CALDEIRA, A D. Modelagem Matemática e a prática dos professores do ensino fundamental e médio. In: I ENCONTRO PARANAENSE DE MODELAGEM EM EDUCAÇÃO MATEMÁTICA, 1., 2004, Londrina. Anais... Londrina: UEL, 2004. 1 CD-ROM.

CHIRÉIA, J V. Trabalhando com a Resolução de Problemas na Educação Básica. 2010. Disponível em: http://ww.diaadiaeducacao.pr.gov.br/portals/pde/arquivos/74-4.pdf Acessado em: $15 / 05 / 2012$.

Colégio SESI-Ensino Médio: V1 - Projeto e Identidade. Curitiba: SESI/PR, 2011.

. V3 - Proposta Pedagógica. Curitiba: SESI/PR, 2011.

D'AMBROSIO, U. Um enfoque transdisciplinar à educação e à história da matemática In: BICUDO, M.A.V (org.) Educação Matemática: Pesquisa em movimento. São Paulo: Cortez Editora, 2005, Disponível em: http://www.diaadiaeducacao.pr.gov.br/portals/pde/arquivos/74-4.pdf Acessado em: 15/05/2012.

FIORENTINI, D. \& LORENZATO, S. Investigação em Educação Matemática: percursos teóricos e metodológicos. 3. ed. Campinas: Autores Associados. Coleção Formação de Professores, 2009 FREIRE, Paulo. Pedagogia do oprimido. 27 ed. Rio de Janeiro, Paz e Terra, 1987.

FRANCHI, R. H. de O. L. A. Modelagem como Estratégia de Aprendizagem no Cálculo Diferencial e Integral nos Cursos de Engenharia. Rio Claro: Universidade Estadual Paulista, 102 p. Dissertação de Mestrado. 1993.

KILPATRICK, J. Fincando estacas: Uma tentativa de demarcar a Educação Matemática como campo profissional e científico. Tradução de Rosana G. S. Miskulin, Cármen Lúcia B. Passos, Regina C. Grando e Elisabeth A. Araújo. Zetetiké, Campinas, v.4, n.5, p. 99-120, jan./jun. 1996.

LEI DE DIRETRIZES E BASES DA EDUCAÇÃO NACIONAL. LDB N. 9394/96

MANDEL, A. G. A filosofia da matemática. Lisboa: Edições 70, 1994.

MIQUELIN, A.F. Complexidade educacional: 0 caminho da escola para a leitura de mundo. In: SESI PARANÁ: Diálogos com a prática: construções teóricas - Coletânea 1. SESI, Serviço Social da Indústria/PR.

ONUCHIC, L. R, MENINO, F. S Jogo e Resolução de Problemas: O problema de Perelmán. Disponível em:

R. B. E. C. T., vol 6, núm. 1, jan-abr.2013 ISSN - 1982-873X 
http://www2.rc.unesp.br/gterp/sites/default/files/artigos/trab_completo_fernanda.pdf, Acessado em: 09/05/2012.

RIGON, M.C, Prazer em aprender: o novo jeito da escolar. Curitiba: Kairós, 2010.

SMOLE, K C.S. e CENTURIÓN, M. A matemática de jornais e revistas. RPM n. 20, 1992.

VOLQUIND, L. O Processo de Mediação e a Construção do Conhecimento Matemático nas Séries Iniciais In: Educação Matemática em Revista. SBEMRS, Out. 2001

ZORZAN, Adriana Loss. Séries iniciais: metodologia para o ensino da matemática. Erechim-RS. Edifapes, 2004.

Priscila Dombrovski Zen. Professora da Universidade Estadual do Centro-Oeste.

pzen@irati.unicentro.br

Joyce Jaquelinne Caetano. Professora da Universidade Estadual do Centro-Oeste. joyce@irati.unicentro.br 